\title{
AUTHORS REPLY
}

Ref.: Mycophenolate mofetil may protect against Pneumocystis carinii pneumonia in renal transplanted patients. Rev. Inst. Med. trop. S. Paulo, 47(3): 143-145, 2005.

Dear Editor,

We read the Letter to the Editor submitted by Dr. Anne TOTET and co-workers reporting a case of Pneumocystis jirovecii in a transplanted patient six months after switching AZA for MMF. We recently observed, at our transplant unit, new cases of Pneumocystis pneumonia (PP). In one case the patient received MMF for 77 days and it was withdrew due to diarrhea and leucopenia; one month later PP developed. In another case the patient received MMF for only three days and sirolimus was introduced; 75 days later PP developed. A third patient, 19 years after receiving azathioprine and prednisone, developed PP one month after sirolimus was introduced due to chronic allograft nephropathy. A fourth patient received MMF for 50 days after transplantation and developed PP three years later. All patients had good outcome with trimethoprim-sulfamethoxazol treatment. Due to these observations we have now started PP prophylaxis always after MMF withdrawal. It is worth noting that OZ \& HUGHES ${ }^{1}$ reported also a protective role of sirolimus on PP in rats (only $30 \%$ of infected animals had signs of PP) what does not seem to be the case in two of our patients. Dr. TOTET et. al. suggested that MMF may kill MMF sensitive Pneumocystis strains while may have no effect on resistant strains that may grow after MMF withdrawal. Although, this may be considered a plausible explanation it does not jeopardize our hypothesis that MMF is protective against $\mathrm{MMF}^{2}$ because the reported clinical case occurred only after switching MMF for AZA. The description of such a case supports our recent finding of no need for Pneumocystis prophylaxis when MMF treatment is interrupted.

Dr. Luiz Sergio Azevedo Unidade de Transplante Renal, Hospital das Clínicas, FMUSP Av. Dr. Enéas de Carvalho Aguiar 255, Caixa Postal 11273-9 05422-970 São Paulo, SP, Brazil E-mail: 1s.azevedo@terra.com.br

\section{REFERENCES}

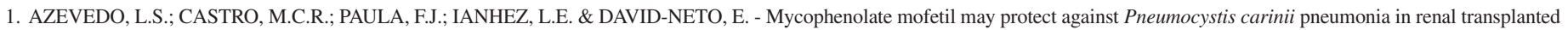
patients. Rev. Inst. Med. trop. S. Paulo, 47: 143-145, 2005.

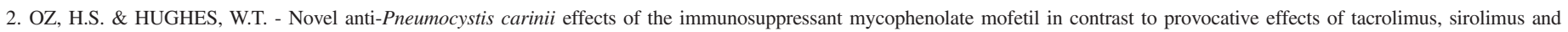
dexamethasone. J. infect. Dis., 175: 901-904, 1997. 